ISSN 2079-6412

www.mdpi.com/journal/coatings

Article

\title{
Fabrication of Nanodiamond Coating on Steel
}

Rafael Velázquez $^{1{ }^{* *} \text {, Victor F. Neto }}{ }^{2}$, Kishore Uppireddi ${ }^{1}$, Brad R. Weiner ${ }^{3}$ and Gerardo Morell ${ }^{1}$

1 Department of Physics, University of Puerto Rico, San Juan, PR 00936-0377, USA;

E-Mails: uppireddi@gmail.com (K.U.); gerardo.morell@upr.edu (G.M.)

2 Department of Mechanical Engineering, Centre for Mechanical Technology \& Automation, University of Aveiro, Campus Universitário de Santiago, Aveiro 3810-193, Portugal;

E-Mail: vfneto@gmail.com

3 Department of Chemistry, University of Puerto Rico, San Juan, PR 00931-3346, USA;

E-Mail: brad@hpcf.upr.edu

* Author to whom correspondence should be addressed; E-Mail: r.velazquez.vicente@gmail.com.

Received: 8 October 2013; in revised form: 18 November 2013 / Accepted: 20 November 2013 /

Published: 2 December 2013

\begin{abstract}
The hardness, heat conductivity and low friction coefficient of microcrystalline diamond make it a suitable candidate for tribological applications. However, its roughness and high deposition temperature pose significant obstacles to these applications. We have successfully grown nanocrystalline diamond on steel at $400{ }^{\circ} \mathrm{C}$ by hot-filament chemical vapor deposition by employing a $\mathrm{CrN}$ interfacial layer. Nanocrystalline diamond combines hardness and surface smoothness required in tribological applications. Microcrystalline diamond and carbon nanotubes can also be grown by controlling the deposition parameters. The fabricated films were characterized with Raman spectroscopy, X-ray diffraction (XRD), Transmission electron microscopy (TEM), and scanning electron microscopy (SEM).
\end{abstract}

Keywords: diamond coating on steel; $\mathrm{CrN}$; hot filament chemical vapor deposition; nanocrystalline diamond; microcrystalline diamond; carbon nanotubes

\section{Introduction}

The superior material properties of synthetic diamond, such as mechanical hardness, high thermal conductivity, high electrical resistivity and broad optical transparency, make it an excellent candidate for diverse coating applications. However, the high diffusion of carbon in iron leads to the formation of 
black carbon (graphite soot) on steel substrates and prevents the deposition of microcrystalline diamond on them [1]. The use of silicon interlayer for the growth of adhered diamond films on steel substrates was reported [2,3]. Buijnsters et al. [4] fabricated high quality and well adhered diamond films on steel substrates using a thin interlayer of $\mathrm{Si}$. Cubic silicon carbide (3C-SiC) was also used as an interlayer to produce well-facetted diamond films with good crystallinity [5,6] but the film delaminated upon post-deposition cooling to room temperature. Ralchenko et al. [7] reported the growth of diamond using a tungsten layer, but this films presented high compressive stress.

Ti-based ceramics such as $\mathrm{Ti}(\mathrm{C}, \mathrm{N}),(\mathrm{Ti}, \mathrm{Al})$ were also employed [8-10] for growing diamond films on steel substrates. The films synthesized on steel substrates using $\mathrm{Ti}$ and $\mathrm{TiC}$ showed promising results [11-14]. Lin and Kuo [15] reported high adhesion and produced good-quality diamond films on steel using electroplated $\mathrm{Ni}$ interlayer. Borges et al. [16] also reported the growth of diamond films on stainless steel 304 substrates with high $\mathrm{Cr}$ content (18 wt \%). They showed that by nitriding the substrates, the amount of $\mathrm{CrN}$ increased on its surface and, during the initial stages of diamond deposition, chromium carbide formed at the substrate due to its carburization facilitating the diamond grown.

Chromium and chromium composites are widely used as interlayers for producing adherent diamond coating on steel [13,17-19]. The use of $\mathrm{CrN}$ as an interlayer has been extensively studied [8,20-27]. Some authors have also used multilayer systems, such as $\mathrm{Ni} / \mathrm{Cu} / \mathrm{Ti}$ [28], Ni/diamond embedded crystallites/Cu [28] and $\mathrm{TiC} / \mathrm{Ti}(\mathrm{C}, \mathrm{N}) / \mathrm{TiN}$ [14] to improve diamond adhesion on steel. The Ni/Cu/Ti interlayer system [28] enabled the growth of good quality diamond films, with good adhesion being confirmed by a $200 \mathrm{~N}$ load indentation using a Rockwell indenter. The multilayer systems consisting $\mathrm{TiC} / \mathrm{Ti}(\mathrm{C}, \mathrm{N}) / \mathrm{TiN}$ [14] were successful in initiating diamond nucleation and diamond crystal growth.

Table 1 presents a summary of the interlayers and interlayer systems used for diamond deposition on steels. The table also provides information on the diamond film quality, this meaning an average classification of the diamond film uniformity, Raman quality, crystallinity, film stress and adhesion of the film to the substrate. Globally, $\mathrm{CrN}$ seems to act as an excellent buffer layer. This also solves the $\mathrm{C}$ intake by iron that prevents diamond growth on its surface. Taking advantage of $\mathrm{CrN}$ as a buffer layer, we hereby report the synthesis of microcrystalline diamond (MCD), nanocrystalline diamond (NCD), and carbon nanotubes (CNTs) on steel at $400{ }^{\circ} \mathrm{C}$ by hot-filament chemical vapor deposition (HFCVD).

Table 1. Summary of interlayers used for diamond deposition on steels. (*Diamond quality depends on: uniformity, Raman quality, crystallinity, film stress and adhesion.)

\begin{tabular}{ccc}
\hline Interlayer(s) & Diamond quality* & Reference \\
\hline $\mathrm{Si}$ & Good & {$[2]$} \\
$\mathrm{Si}$ & Medium & {$[3]$} \\
$\mathrm{Si}$ & Very good & {$[4]$} \\
$3 \mathrm{C}-\mathrm{SiC}$ & Medium & {$[5]$} \\
Metal-diamond composite & Good & {$[5]$} \\
$\mathrm{SiC}$ & Medium & {$[6]$} \\
Ni-diamond composite & Good & {$[6]$} \\
Cr-diamond composite & Good & {$[6]$} \\
\hline
\end{tabular}


Table 1. Cont.

\begin{tabular}{ccc}
\hline Interlayer(s) & Diamond quality* & Reference \\
\hline $\mathrm{W}$ & Good & {$[7]$} \\
$\mathrm{CrNi}$ & No film & {$[8]$} \\
$\mathrm{TiN}$ & No film & {$[8]$} \\
$\mathrm{Ti}(\mathrm{C}, \mathrm{N})$ & No film & {$[8]$} \\
$(\mathrm{Ti}, \mathrm{Al}) \mathrm{N}$ & No film & {$[8]$} \\
$\mathrm{CrN}$ & No film & {$[8]$} \\
$\mathrm{WC} / \mathrm{C}$ & No film & {$[8]$} \\
$\mathrm{TiN}$ & Medium & {$[9]$} \\
$\mathrm{TiN}$ & Medium & {$[10]$} \\
$\mathrm{Ti}$ & Good & {$[11-13]$} \\
$\mathrm{Cr}$ & Good & {$[13,14]$} \\
$\mathrm{ZrN}$ & Medium & {$[14]$} \\
$\mathrm{ZrC}$ & Medium & {$[14]$} \\
$\mathrm{TiC} / \mathrm{Ti}(\mathrm{C}, \mathrm{N}) / \mathrm{TiN}$ & Medium & {$[14]$} \\
$\mathrm{TiC}$ & Good & {$[14]$} \\
$\mathrm{Ni}$ & Good & {$[15]$} \\
$\mathrm{Ni} / \mathrm{Ni}-\mathrm{diamond} \mathrm{composite}$ & Good & {$[16]$} \\
$\mathrm{N}$ & Good & {$[17]$} \\
$\mathrm{N}(\mathrm{CrN})$ & Good & {$[16]$} \\
$\mathrm{Cr}$ & Good & {$[17]$} \\
$\mathrm{CrC}$ & Good & {$[18,19]$} \\
$\mathrm{CrN}$ & Good & {$[20-27]$} \\
$\mathrm{B}$ & Good & {$[26,27]$} \\
$\mathrm{Ni} / \mathrm{Cu} / \mathrm{Ti}$ & Medium & \\
& &
\end{tabular}

\section{Experimental Section}

The films were grown on $25 \mathrm{~mm}^{2} \mathrm{Cr}_{2} \mathrm{~N}$-coated steel substrates in the HFCVD reactor that was previously described in detail [29]. The steel samples (AISI P20 modified; composition (wt \%): C 0.37; Si 0.30; Mn 1.40; Cr 2.00; Mo 0.20; Ni 1.00; $\mathrm{S} \leq 0.010$ ) were pre-coated with a commercial grade sputtered chromium nitride $\sim 2 \mu \mathrm{m}$ thick film. Prior to the diamond deposition, the substrates were seeded with diamond powder $<0.1 \mu \mathrm{m}$. After seeding, the substrates were ultrasonically cleaned in methanol for $20 \mathrm{~min}$, then dried in air at room temperature and placed on a Mo substrate holder integrated with a pyrolytic graphite heater. The chamber was evacuated to $8 \times 10^{-4} \mathrm{~Pa}\left(6 \times 10^{-6}\right.$ Torr $)$ before admitting the reactive gas mixture consisting of $2 \% \mathrm{CH}_{4}$ and $98 \% \mathrm{H}_{2}$ with $500 \mathrm{ppm}_{2} \mathrm{~S}$. The total gas pressure was kept at $2700 \mathrm{~Pa}$ (20 Torr) during growth. The temperature of the rhenium filament was kept at $2500{ }^{\circ} \mathrm{C}$ and it was positioned at $8-9 \mathrm{~mm}$ above the substrates. The substrate temperature was kept at $400-500{ }^{\circ} \mathrm{C}[30]$ and the films were grown for $2-4 \mathrm{~h}$ (see Table 2). 
Table 2. HFCVD growth parameters employed and carbon materials grown.

\begin{tabular}{ccc}
\hline Material Grown & Substrate Temperature & Deposition Time \\
\hline MCD & $400{ }^{\circ} \mathrm{C}$ & $2 \mathrm{~h}$ \\
$\mathrm{NCD}$ & $400{ }^{\circ} \mathrm{C}$ & $4 \mathrm{~h}$ \\
$\mathrm{CNTs}$ & $500{ }^{\circ} \mathrm{C}$ & $2 \mathrm{~h}$ \\
\hline
\end{tabular}

The samples were characterized by Scanning Electron Microscopy (SEM Model 35 CF microscope, JEOL, Tokyo, Japan), TEM (LEO 922 OMEGA microscope operating at an accelerating voltage of 200 kV, Carl Zeiss, Jena, Germany), and Raman spectroscopy (ISA J Y Model T64000, HORIBA, Kyoto, Japan) using the $514.5 \mathrm{~nm}$ line of Ar-ion laser. The crystal structure was determined by $\theta-2 \theta$ scans obtained by the X-ray powder diffractometry method (Siemens D5000 diffractometer, $\mathrm{Cu}$ $\mathrm{K} \alpha \sim 1.5405 \AA$ A, Siemens, Munich, Germany).

\section{Results and Discussion}

Raman spectroscopy was used to characterize the carbon films synthesized on steel substrates using $\mathrm{CrN}$ as buffer layer (see Figure 1). The sharp peak at around $1333 \mathrm{~cm}^{-1}$ in Figure 1a corresponds to the stretching vibration of the tetrahedrally $\left(\mathrm{sp}^{3}\right)$ bonded diamond lattice that is a conclusive characteristic of MCD structure [30]. In Figure 1b, the bands at $1336 \mathrm{~cm}^{-1}$ and $1586 \mathrm{~cm}^{-1}$ are characteristic of sp hybridized carbon (diamond) and $\mathrm{sp}^{2}$ hybridized carbon (graphite), respectively. The band at $\sim 1360 \mathrm{~cm}^{-1}$ corresponds to disorder-induced in $\mathrm{sp}^{2} \mathrm{C}$ and is known as D-band, while the bands at 1136 and $1477 \mathrm{~cm}^{-1}$ together indicate the presence of transpolyacetylene (TPA) [31]. These Raman features in Figure $1 \mathrm{~b}$ indicate the fabrication of NCD films. Hence, MCD and NCD films were obtained on the $\mathrm{CrN}$-covered steel substrates at $400{ }^{\circ} \mathrm{C}$, depending on the deposition time. However, when the substrate temperature is increased to $500{ }^{\circ} \mathrm{C}$, the Raman signatures change significantly as shown in Figure 1c. There is no indication of $\mathrm{sp}^{3} \mathrm{C}$, the TPA bands disappear, well-defined $\mathrm{D}$ and $\mathrm{G}$ bands are present, and new low-frequency bands appear (Figure 1c). The bands in the $100-400 \mathrm{~cm}^{-1}$ range are the radical breathing modes (RBM) of single-wall CNTs [32,33]. The diameter of an isolated single wall CNT is inversely proportional to the RBM frequency $(\omega), d(\mathrm{~nm})=A / \omega\left(\mathrm{cm}^{-1}\right)$, where $d=$ diameter of single-wall CNTs, $A$ is the proportionality constant equal to 223.75 [34].Using this equation, the diameters of CNTs were calculated to be $1.0 \mathrm{~nm}$ for the RBM peak at $222.8 \mathrm{~cm}^{-1}, 0.8 \mathrm{~nm}$ for the RBM peak at $283 \mathrm{~cm}^{-1}$, and $0.6 \mathrm{~nm}$ for the RBM peak at $396.9 \mathrm{~cm}^{-1}$. Moreover, the ratio of intensity of the G-band to the D-band $\left(I_{\mathrm{G}} / I_{\mathrm{D}}\right)$ gives an indication of the quality of the CNTs. The higher the intensity ratio is, the better quality nanotubes film [35]. In the present case, $I_{\mathrm{G}} / I_{\mathrm{D}}>1$, revealing that the fabricated CNTs are not highly disordered CNTs [36]. Hence, the Raman spectrum shows that single-wall CNTs were fabricated on $\mathrm{CrN} /$ steel at a substrate temperature of $500{ }^{\circ} \mathrm{C}$.

SEM images (Figure 2) reveal the evolution of the carbon films' microstructure as a function of temperature and time. Figure $2 \mathrm{a}, \mathrm{b}$ clearly shows the grainy structure of the MCD films, with crystallite sizes around $0.5-1.0 \mu \mathrm{m}$. The NCD films (Figure 2c,d) are composed of micro scale size clusters, which in turn are made of nanocrystallites and nanofibers. In the case of CNT films, Figure 2e,f, the SEM images show uniformly coated spaghetti-like carbon nanotubes films. The inset in Figure $2 \mathrm{f}$ shows the TEM image of a single-wall CNT. Multi- and single-wall CNTs, large and small, co-exist in these CNT films. 
Figure 1. Raman spectra of materials grown on $\mathrm{CrN}$-coated stainless steel substrates: (a) $\mathrm{MCD} / \mathrm{CrN} / \mathrm{Steel}$; (b) NCD/CrN/Steel; and (c) CNT/CrN/Steel.
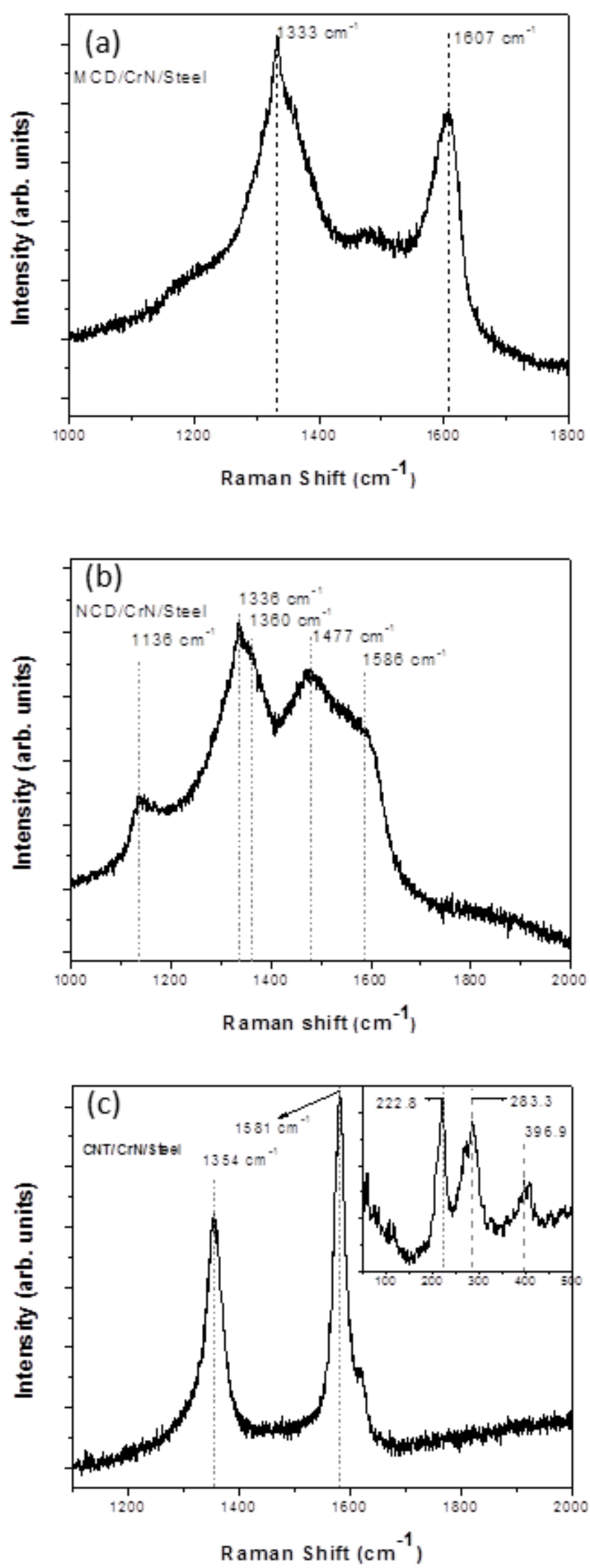
Figure 2. SEM images of materials grown on $\mathrm{CrN}$-coated stainless steel substrates: (a,b) $\mathrm{MCD} / \mathrm{CrN} / \mathrm{Steel}$; (c,d) $\mathrm{NCD} / \mathrm{CrN} / \mathrm{Steel}$; and (e,f) $\mathrm{CNT} / \mathrm{CrN} / \mathrm{Steel}$. The inset in (f) shows the TEM image of a single-wall CNT.
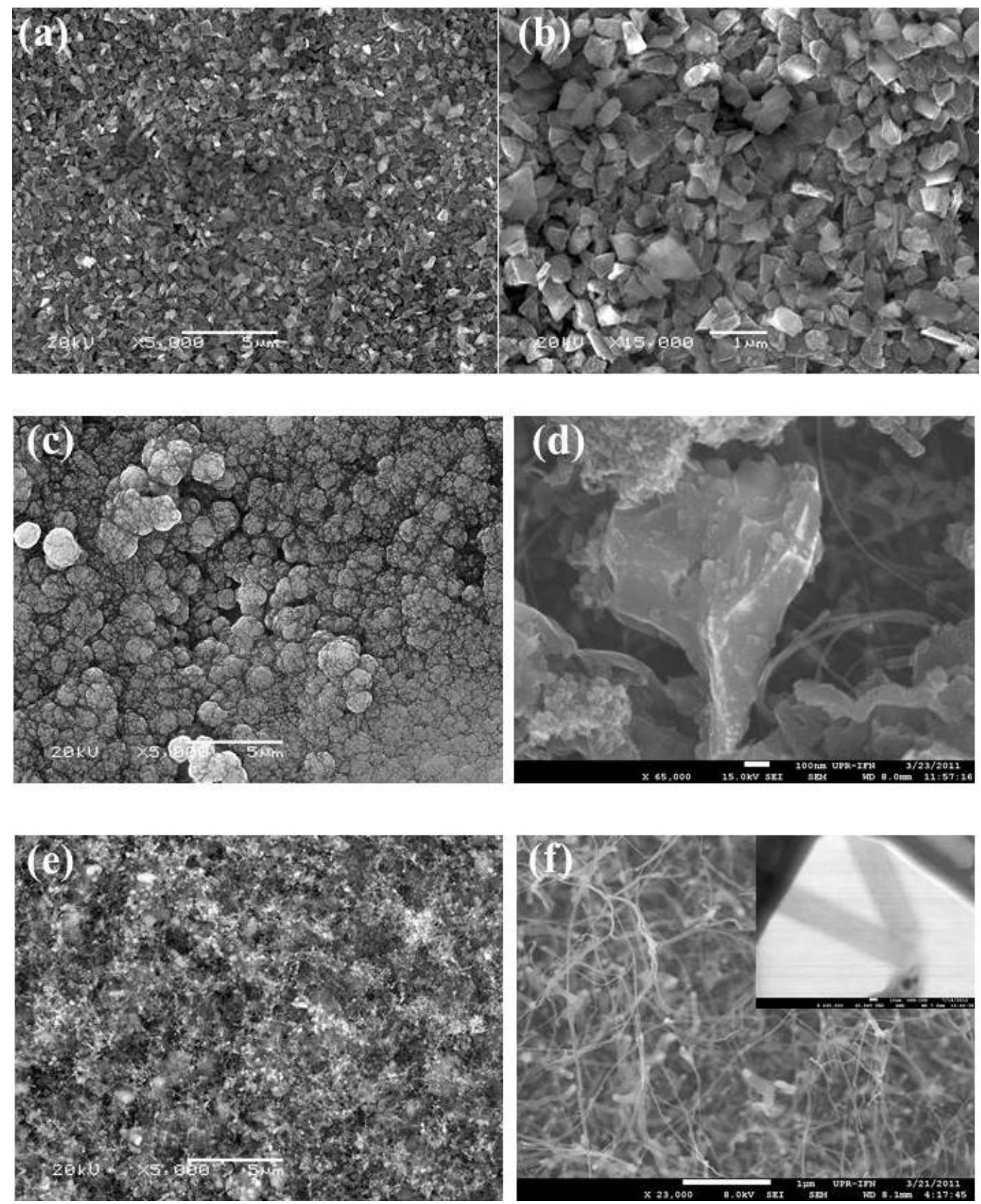

XRD diffractograms (Figure 3) help to elucidate the material transformations that take place in the substrate surface that lead the formation of CNTs. The XRD of the original $\mathrm{Cr}_{2} \mathrm{~N} /$ steel substrate shows the $\mathrm{Cr}_{2} \mathrm{~N}$ (101), $\mathrm{Cr}_{2} \mathrm{~N}$ (110) and Fe (110) peaks (Figure 3a), as identified using standard JCPDS data (Joint Committee on Powder Diffraction Standards). Under CVD conditions at $400{ }^{\circ} \mathrm{C}$ for $2 \mathrm{~h}$, the synthesis of $\mathrm{MCD}$ (peak $\sim 4^{\circ}$ ) takes place and the $\mathrm{Cr}_{2} \mathrm{~N}$ is partially transformed into $\mathrm{CrN}$ (Figure 3b) [25]. After $4 \mathrm{~h}$ at $400{ }^{\circ} \mathrm{C}$, an $\mathrm{NCD}$ layer covers the $\mathrm{MCD}$, and $\mathrm{Cr}_{2} \mathrm{~N}$ completely disappears into $\mathrm{CrN}$ (Figure $3 \mathrm{c}$ ). At higher temperatures $\left(500{ }^{\circ} \mathrm{C}\right)$ there is enough thermal energy for the $\mathrm{C}$ containing species to react with $\mathrm{CrN}$ to yield defect- $\mathrm{C}_{3} \mathrm{~N}_{4}, \mathrm{C}_{6} \mathrm{~N}_{2}$, and free $\mathrm{Cr}$ (Figure 3c) [25,36,37]. As a result, Cr nanoparticles become available at the substrate surface to act as catalysts for the synthesis of CNTs [38]. 
From the above discussion, it is concluded that the $\mathrm{Cr}_{2} \mathrm{~N}$ buffer layer is useful for the synthesis of micro- and nano-crystalline diamond films at temperatures around $400{ }^{\circ} \mathrm{C}$, but it yields catalyst particles for the synthesis of CNTs at higher temperatures. In previous works [39-42], polycrystalline diamond was deposited at higher temperatures on the same substrate interlayer system, although not using $\mathrm{H}_{2} \mathrm{~S}$. These samples were typically deposited at a surface temperature of about $750{ }^{\circ} \mathrm{C}$ which led to high compressive stress of the grown films, but no CNTs were detected. In the present case, $\mathrm{H}_{2} \mathrm{~S}$ leads to the formation of $\mathrm{C}-\mathrm{S}$ radicals in the heat-activated volume around the filament, which turns back into $\mathrm{H}_{2} \mathrm{~S}$ in the cooler region above the substrate, while leaving $\mathrm{C}$ atoms deposited on the substrate surface [43]. This process results in additional $\mathrm{C}$-transport mechanism to the substrate that enhances the deposition of $\mathrm{C}$ atoms. Moreover, at the growing surface, sulfur acts as a cross-linker that promotes the formation of graphitic bonds at the growing surface before it is released back to the vapor phase [44].

Figure 3. XRD of (a) CrN-coated steel substrate, (b) MCD/CrN/Steel, (c) NCD/CrN/Steel, and (d) CNT/CrN/Steel.
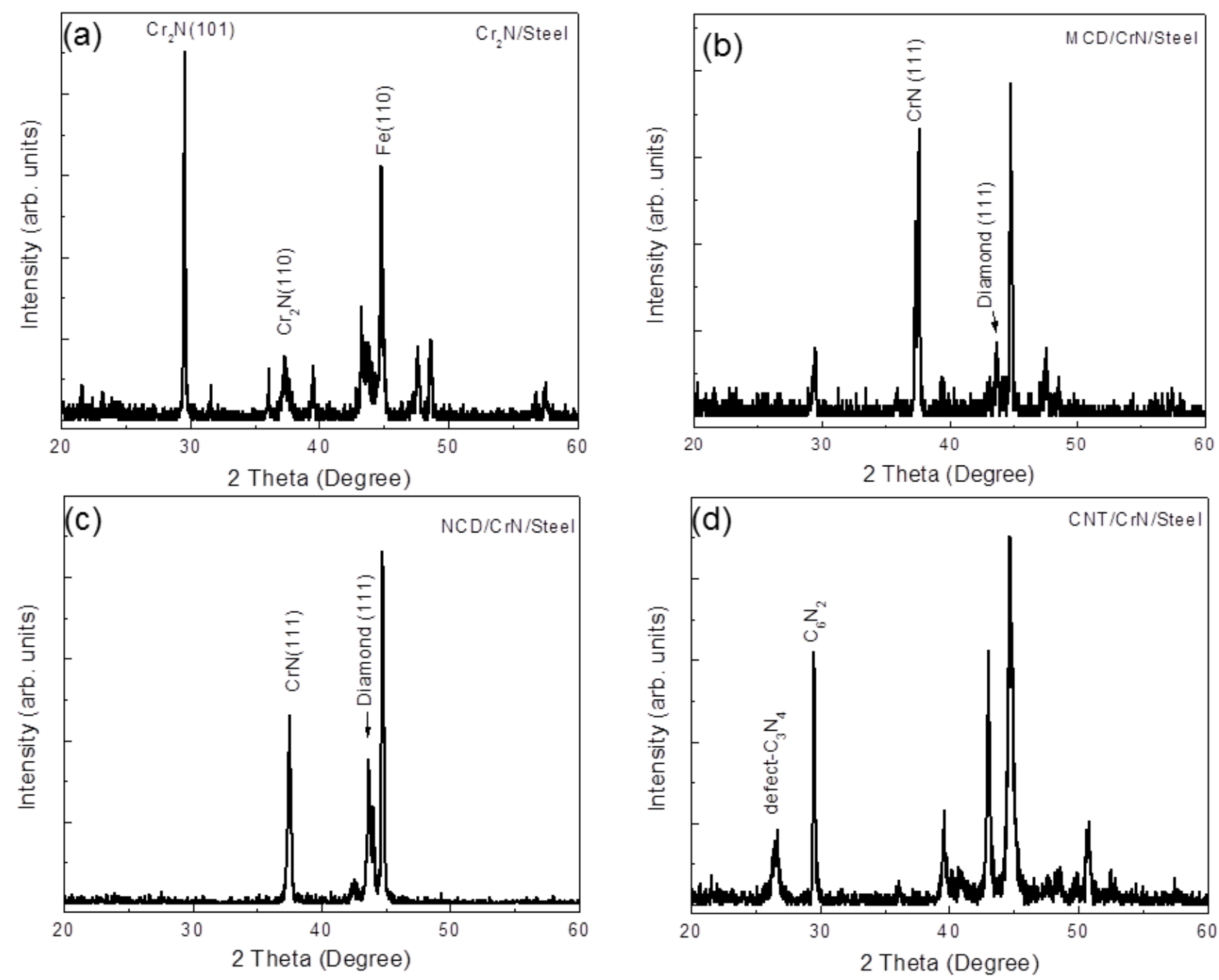


\section{Conclusions}

It has been shown that it is possible to grow a nanocrystalline diamond coating on steel at $400{ }^{\circ} \mathrm{C}$ by HFCVD using $\mathrm{Cr}_{2} \mathrm{~N}$ as buffer layer and trace amounts of $\mathrm{H}_{2} \mathrm{~S}$. Microscrystalline diamond and carbon nanotubes can also be grown by controlling the deposition parameters. However, nanocrystalline diamond provides a smooth and hard surface unlike microcrystalline diamond or carbon nanotubes. The substrate temperature and deposition time are the critical parameters to control the type of carbon material that is grown. This process can enable the fabrication of nanodiamond-coated tools and other tribological applications.

\section{Acknowledgments}

This research was carried out under the auspices of the Institute for Functional Nanomaterials (NSF Cooperative Agreement 1002410), GK-12 (NSF Grant 0841338), PR NASA EPSCoR (NASA Cooperative Agreement NNX13AB22A). V.F. Neto acknowledges the "Fundação para a Ciencia e Tecnologia" (Portugal) for his post-doctoral research grant (SFRH/BPD/44978/2008). We also want to acknowledge the help of William Pérez (Raman Spectroscopy), Javier Palomino Garate (Transmission Electron Microscopy), and Josué Ortiz (Scanning Electron Microscopy).

\section{Conflicts of Interest}

The authors declare no conflict of interest.

\section{References}

1. Neto, V.F.; Vaz, R.; Ali, N.; Oliveira, M.S.A.; Grácio, J.; Ghumman, C.A.A.; Teodoro, O.M.N.D. Carbon diffusion into steel during diamond chemical vapour deposition. Int. J. Nanomanufacturing 2008, 2, 192-203.

2. Chen, H.; Nielsen, M.L.; Gold, C.J.; Dillon, R.O.; DiGregorio, J.; Furtak, T. Growth of diamond films on stainless steel. Thin Solid Films 1992, 212, 169-172.

3. Fenker, M.; Ferber, H.; Füßer, H.-J.; Jörgensen, G.; Lahres, M.; Wolf, G.K. Deposition of CVD diamond onto ion beam modified ASP 23 cutting tools. Surf. Coatings Technol. 1998, 98, 1053-1059.

4. Buijnsters, J.G.; Shankar, P.; van Enckevort, W.J.P.; Schermer, J.J.; ter Meulen, J.J. The applicability of ultra thin silicon films as interlayers for CVD diamond deposition on steels. Phys. Stat. Sol. A 2003, 195, 383-395.

5. Klages, C.-P.; Fryda, M.; Matthke, T.; Schäfer, L.; Dimigen, H. Diamond coatings and cBN coatings for tools. Int. J. Refract. Met. Hard Mater. 1998, 16, 171-176.

6. Schäfer, L.; Fryda, M.; Stolley, T.; Xiang, L.; Klages, C.-P. Chemical vapour deposition of polycrystalline diamond films on high-speed steel. Surf. Coatings Technol. 1999, 116-119, 447-451.

7. Ralchenko, V.G.; Smolin, A.A.; Pereverzev, V.G.; Obraztsova, E.D.; Korotoushenko, K.G.; Konov, V.I.; Lakhotkin, Y.V.; Loubnin, E.N. Diamond deposition on steel with CVD tungsten intermediate layer. Diam. Relat. Mater. 1995, 4, 754-758.

8. Haubner, R.; Lux, B. Diamond deposition on steel substrates using intermediate layers. Int. J. Refract. Met. Hard Mater. 2006, 24, 380-386. 
9. Weiser, P.S.; Prawer, S. Chemical vapour deposition of diamond onto iron based substrates-The use of barrier layers. Diam. Relat. Mater. 1995, 4, 710-713.

10. Lorenz, H.P. Investigation of TiN as an interlayer for diamond deposition on steel. Diam. Relat. Mater. 1995, 4, 1088-1092.

11. Fan, Q.H.; Fernandes, A.; Gracio, J. Diamond coating on steel with a titanium interlayer. Diam. Relat. Mater. 1998, 7, 603-606.

12. Fan, Q.H.; Fernandes, A.; Pereira, E.; Grácio, J. Adhesion of diamond coatings on steel and copper with a titanium interlayer. Diam. Relat. Mater. 1999, 8, 1549-1554.

13. Silva, F.J.G.; Baptista, A.P.M.; Pereira, E.; Teixeira, V.; Fan, Q.H.; Fernandes, A.J.S.; Costa, F.M. Microwave plasma chemical vapour deposition diamond nucleation on ferrous substrates with Ti and Cr interlayers. Diam. Relat. Mater. 2002, 11, 1617-1622.

14. Polini, R.; Mantini, F.P.; Braic, M.; Amar, M.; Ahmed, W.; Taylor, H. Effects of Ti- and Zr-based interlayer coatings on the hot filament chemical vapour deposition of diamond on high speed steel. Thin Solid Films 2006, 494, 116-122.

15. Lin, C.R.; Kuo, C.T. High adhesion and quality diamond films on steel substrate. Diam. Relat. Mater. 1998, 7, 903-907.

16. Borges, C.F.M.; Pfender, E.; Heberlein, J. Influence of nitrided and carbonitrided interlayers on enhanced nucleation of diamond on stainless steel 304. Diam. Relat. Mater. 2001, 10, 1983-1990.

17. Barei $\beta$, C.; Perle, M.; Rosiwal, S.M.; Singer, R.F. Diamond coating of steel at high temperatures in hot filament chemical vapour deposition (HFCVD) employing chromium interlayers. Diam. Relat. Mater. 2006, 15, 754-760.

18. Schwarz, S.; Musayev, Y.; Rosiwal, S.M.; Schaufler, C.; Singer, R.F.; Meerkamm, H. Diam. Relat. Mater. 2002, 11, 757-762.

19. Schwarz, S.; Rosiwal, S.M.; Musayev, Y.; Singer, R.F. High temperature diffusion chromizing as a successful method for CVD-diamond coating of steel—Part II. Diam. Relat. Mater. 2003, 12, 701-706.

20. Fayer, A.; Glozman, O.; Hoffman, A. Deposition of continuous and well adhering diamond films on steel. Appl. Phys. Lett. 1995, 67, 2299-2301.

21. Glozman, O.; Berner, A.; Shechtman, D.; Hoffman, A. Influence of Cr-N interlayer properties on the initial stages of CVD diamond growth on steel substrates. Diam. Relat. Mater. 1998, 7, 597-602.

22. Glozman, O.; Halperin, G.; Etsion, I.; Berner, A.; Shectman, D.; Lee, G.H.; Hoffman, A. Study of the wear behavior and adhesion of diamond films deposited on steel substrates by use of a $\mathrm{Cr}-\mathrm{N}$ interlayer. Diam. Relat. Mater. 1999, 8, 859-864.

23. Glozman, O.; Hoffman, A. Adhesion improvement of diamond films on steel subtrates using chromium nitride interlayers. Diam. Relat. Mater. 1997, 6, 796-801.

24. Avigal, Y.; Glozman, O.; Etsion, I.; Halperin, G.; Hoffman, A. [100]-Textured diamond films for tribological applications. Diam. Relat. Mater. 1997, 6, 381-385.

25. Buijnsters, J.G.; Shankar, P.; Fleischer, W.; van Enckevort, W.J.P.; Schermer, J.J.; ter Meulen, J.J. CVD diamond deposition on steel using arc-plated chromium nitride interlayers. Diam. Relat. Mater. 2002, 11, 536-544.

26. Silva, F.J.G.; Fernandes, A.J.S.; Costa, F.M.; Baptista, A.P.M.; Pereira, E. A new interlayer approach for CVD diamond coating of steel substrates. Diam. Relat. Mater. 2004, 13, 828-833. 
27. Silva, F.J.G.; Fernandes, A.J.S.; Costa, F.M.; Teixeira, V.; Baptista, A.P.M.; Pereira, E. Tribological behaviour of CVD diamond films on steel substrates. Wear 2003, 255, 846-853.

28. Silva, F.J.G.; Fernandes, A.J.S.; Costa, F.M.; Baptista, A.P.M.; Pereira, E. Unstressed PACVD diamond films on steel pre-coated with a composite multilayer. Surf. Coatings Technol. 2005, 191, 102-107.

29. Gupta, S.; Weiss, B.L.; Weiner, B.R.; Morell, G. Study of the electron field emission and microstructure correlation in nanocrystalline carbon thin films. J. Appl. Phys. 2001, 89, 5671-5675.

30. Piazza, F.; Gonzalez, J.A.; Velazquez, R.; De Jesus, J.; Rosario, S.A.; Morell, G. Diamond film synthesis at low temperature. Diam. Relat. Mater. 2006, 15, 109-116.

31. Ferrari, A.C.; Robertson, J. Raman spectroscopy of amorphous, nanostructured, diamond-like carbon, and nanodiamond. Phil. Trans. R. Soc. Lond. A 2004, 362, 2477-2512.

32. Islam, S.S.; Shah, K.A.; Mavi, H.S.; Shaukla, A.K.; Rath, S.; Harsh, S. Raman study on single-walled carbon nanotubes with different laser excitation energies. Bull. Mater. Sci. 2007, 30, 295-299.

33. Bandow, S.; Asaka, S.; Saito, Y.; Rao, A.M.; Grigorian, L.; Richter, E.; Eklund, P.C. Effect of the growth temperature on the diameter distribution and chirality of single-wall carbon nanotubes. Phys. Rev. Lett. 1998, 80, 3779-3782.

34. Kobayashi, Y.; Takayuki, T.; Ueno, Y.; Niwa, O.; Homma, Y.; Ogino, T. Extremely intense Raman signals from single-walled carbon nanotubes suspended between Si nanopillars. Chem. Phys. Lett. 2004, 386, 153-157.

35. Wei, J.; Yung, K.P.; Tay, B.K. Formation of CNT bumps for interconnection applications. SIMTech Tech. Rep. 2009, 10, 76-79.

36. Uebing, C.; Viefhaus, H.; Grabke, H.J. Formation of CrN surface compounds and surface precipitates on Fe-15\%Cr-N single crystals. Appl. Surf. Sci. 1988, 32, 363-380.

37. Martin-Gil, J.; Matin-Gil, F.J.; Sarikaya, M.; Qian, M.; Jose-Yacaman, M.; Rubio, A. Evidence of a low compressibility carbon nitride with defect-zincblende structure. J. Appl. Phys. 1997, 81, 2555-2559.

38. Keller, T.M.; Laskoski, M.; Osofsky, M.; Qadri, S.B. Carbon nanotube formation catalyzed by Ni nanoparticles in carbonaceous solid. Phys. Stat. Sol. A 2008, 205, 1585-1591.

39. Neto, V.F.; Vaz, R.; Oliveira, M.S.A.; Grácio, J. CVD diamond-coated steel inserts for thermoplastic mould tools - Characterization and preliminary performance evaluation. J. Mater. Process. Technol. 2009, 209, 1085-1091.

40. Neto, V.F.; Vaz, R.; Ali, N.; Oliveira, M.S.A.; Grácio, J. Performance of sub-micron diamond films coated on mould inserts for plastic injection moulding. J. Mater. Sci. 2008, 43, 3392-3399.

41. Neto, V.F.; Vaz, R.; Ali, N.; Oliveira, M.S.A.; Grácio, J. Diamond coatings on 3D structured steel. Diam. Relat. Mater. 2008, 17, 1424-1428.

42. Neto, V.F.; Oliveira, M.S.A.; Ali, N.; Grácio, J. Time-modulated chemical vapour deposition diamonf on mould making 2738 steel. Vacuum 2008, 82, 1346-1349.

43. Haubner, R.; Sommer, D. Hot-filament diamond deposition with sulfur addition. Diam. Relat. Mater. 2003, 12, 298-305.

44. Oberlin, A. Carbonization and graphitization. Carbon 1984, 22, 521-541.

(C) 2013 by the authors; licensee MDPI, Basel, Switzerland. This article is an open access article distributed under the terms and conditions of the Creative Commons Attribution license (http://creativecommons.org/licenses/by/3.0/). 